\title{
Investigations on intra-annual elevation changes using multi-temporal airborne laser scanning data: case study Engabreen, Norway
}

\author{
Thomas GEIST, ${ }^{1}$ Hallgeir ELVEHØY, ${ }^{2}$ Miriam JACKSON, ${ }^{2}$ Johann STÖTTER ${ }^{1}$ \\ ${ }^{1}$ Institute of Geography, University of Innsbruck, Innrain 52, A-6020 Innsbruck, Austria \\ E-mail: thomas.geist@uibk.ac.at \\ ${ }^{2}$ Norwegian Water Resources and Energy Directorate (NVE), PO Box 5091 Majorstua, NO-0301 Oslo, Norway
}

\begin{abstract}
Key issues of glacier monitoring are changes in glacier geometry and glacier mass. As accurate direct measurements are costly and time-consuming, the use of various remote-sensing data for glacier monitoring is explored. One technology used and described here is airborne laser scanning. The method enables the derivation of high-quality digital elevation models (DEMs) with a vertical and horizontal accuracy in the sub-metre range. Between September 2001 and August 2002, three laser scanner data acquisition flights were carried out, covering the whole area of Engabreen, Norway, and corresponding well to the measurement dates for the mass-balance year 2001/02. The data quality of the DEMs is assessed (e.g. by comparing the values with a control area which has been surveyed independently or GPS ground profiles measured during the flights). For the whole glacier, surface elevation change and consequently volume change is calculated, quantified and compared with traditional mass-balance data for the same time interval. For the winter term, emergence/submergence velocity is determined from laser scanner data and snow-depth data and is compared with velocity measurements at stakes. The investigations reveal the high potential of airborne laser scanning for measuring the extent and the topography of glaciers as well as changes in geometry ( $\Delta$ area, $\Delta$ volume).
\end{abstract}

\section{INTRODUCTION}

Monitoring of glacier behaviour offers valuable information about climate change and is interesting for many practical applications (e.g. hydropower production, natural hazard forecasting, agriculture and tourism). Changes in glacier geometry and glacier mass are key issues for glacier monitoring. The traditional methods of in situ mass-balance measurements (e.g. Kaser and others, 2003) allow for only limited spatial coverage and are both time- and labourintensive. However, airborne and satellite remote-sensing methods have the potential for accurate mass-balance estimates for wider areas. Hence, various remote-sensing techniques for glacier monitoring have been explored (e.g. Bamber and Kwok, 2003).

The investigations presented here are part of the European Union-financed OMEGA (Operational Monitoring of European Glacial Areas) project, the main objective of which is to develop an operational monitoring system for glaciers using different airborne and space-borne remote-sensing methods (Pellikka and others, 2001). One method investigated was airborne laser scanning, with the aim of exploring the potential and the limitations of this technology for applications in glaciology, and providing data for the calibration and validation of other methods (Geist and others, 2003).

In practice, the use of aerial photography is the most common remote-sensing tool supporting glaciological work (e.g. Andreassen and others, 2002). Besides the optical information, a photogrammetric evaluation of aerial photograph stereo pairs can provide information on the surface geometry and, when applied multi-temporally, changes in glacier area and volume, and consequently mass balance. Although the influence of limited ground control can be reduced with modern processing methods, this technology still has significant limitations, for example in firn areas, where low texture differences prevent accurate measurements of the surface. Airborne laser scanning is a means to overcome this limitation.

Engabreen $\left(66^{\circ} 40^{\prime} \mathrm{N}, 13^{\circ} 45^{\prime} \mathrm{E}\right)$, a $40 \mathrm{~km}^{2}$ northern outlet of the western Svartisen ice cap, is the OMEGA study glacier in Norway (Fig. 1). It covers an altitude range from $1575 \mathrm{~m}$ (at Snøtind) down to $10 \mathrm{~m}$ (at Engabrevatnet). The glacier tongue $(3 \mathrm{~km}$ long) declines from 900 to $10 \mathrm{~m}$ a.s.l. through an icefall. Engabreen is situated in a maritime climate close to the Atlantic coast in Nordland, northern Norway. Annual precipitation in the area is $>2000 \mathrm{~mm}$. Mass-balance measurements have been performed annually since 1970 . Mean winter and summer balances (1970-2003) are 2.93 and $-2.30 \mathrm{~m}$ w.e., and the mean equilibrium-line altitude is $1086 \mathrm{~m}$ a.s.l. Front position changes have been monitored since 1903.

\section{METHOD}

\section{Airborne laser scanning}

During the last decade, airborne laser scanning has gone through decisive technical improvements and thus has become a standard and well-accepted method for the acquisition of topographic data for many applications. The method is characterized by a far-reaching degree of automation for both data recording and data pre-processing.

Airborne laser scanning integrates a global positioning system (GPS) receiver for determining the position of the sensor, an inertial navigation system (INS) for determining the attitude of the sensor, and a scanning device using laser technology mounted in an aeroplane. All components are time-synchronized and provide a means to measure the distance between the aircraft and the Earth's surface. With 

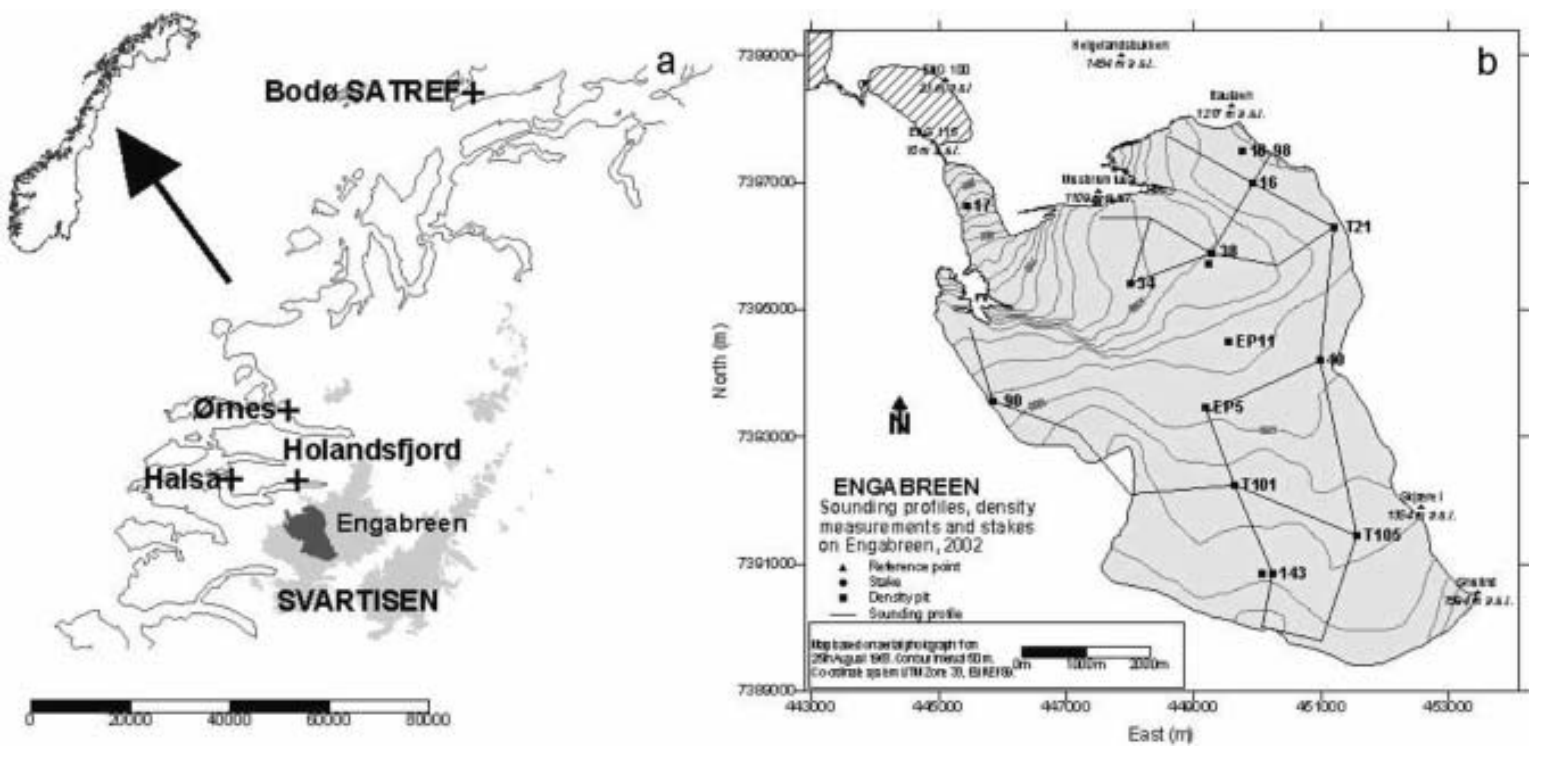

Fig. 1. (a) Map of the study area, with relevant locations for the investigations presented here. (b) Locations of sounding profiles, density measurements and stakes.

the laser scanning system used in this study (Optech Airborne Laser Terrain Mapper (ALTM)), the laser beam is swept perpendicular to the ground track, thus producing a more-or-less even distribution of data points. Both density and distribution of the data points depend on scan angle, scan frequency, height above ground, aircraft speed, swath overlap and reflectance characteristics of the scanned surface. Ackermann (1999) and Kraus (2004) provide comprehensive overviews on laser scanning technology. The method enables the derivation of high-quality digital elevation models (DEMs) with a vertical and horizontal accuracy in the sub-metre range.

The main application of airborne laser scanning technology is topographic surveying, especially in wooded areas. Since most glaciers are located in high mountain areas, there are special conditions for the applications of airborne laser scanning. The rugged topography with large elevation differences over short distances necessitates expert navigation skills and can cause problems with airborne laser scanning systems with limited range for data acquisition. In addition, the complex and sometimes rapidly changing weather conditions can cause problems for on-sight navigation of the plane and thus can force interruptions of data acquisition campaigns.

To date, laser altimetry for glaciological purposes has been widely and successfully applied on the Greenland ice sheet (e.g. Krabill and others, 1995; Thomas and others, 2000; Abdalati and others, 2002) and in Antarctica

Table 1. System parameters for the airborne laser scanner (Optech ALTM 1225) data acquisition campaigns at Engabreen

$\begin{array}{ll}\text { Measuring frequency } & 25000 \mathrm{~Hz} \\ \text { Scan frequency } & 25 \mathrm{~Hz} \\ \text { Laser wavelength } & \sim 1.05 \mu \mathrm{m} \\ \text { Scan angle } & \pm 20^{\circ} \\ \text { Average flying altitude } & 900 \mathrm{~m} \\ \text { Number of overlapping scan swaths } & 31\end{array}$

(e.g. Spikes and others, 2003), but only a few attempts have been made to utilize airborne laser scanning on mountain glaciers (e.g. Echelmeyer and others, 1996; Kennett and Eiken, 1997; Aðalgeirsdóttir and others, 1998; Favey and others, 1999).

\section{Data acquisition and processing}

At Svartisen, four laser-scanner data acquisition flights were planned and organized by the Institute of Geography, University of Innsbruck, and carried out by TopScan GmbH, Rheine, Germany, covering $62 \mathrm{~km}^{2}$ of the Svartisen ice cap including the whole of Engabreen between September 2001 and June 2003. The first three flights (September 2001, May 2002 and August 2002) correspond to measurement dates for a shortened glacier mass-balance year 2001/02 and are analyzed in this study. The main technical parameters of the sensor are shown in Table 1. The realized average distance between the data points (coordinates) is $1.4 \mathrm{~m}$ for all three datasets.

GPS reference data were collected at geodetic points close to the glacier (Holandsfjord and Ørnes; see Fig. 1), and at a permanent receiving station (SATREF Bodø). A football field at Halsa (see Fig. 1) was used as the control area. A DEM based on a tacheometer survey of the football field before the first data acquisition flight was used to calculate the elevation accuracy of the laser scanner measurements (see below). The football field was scanned before and after each data acquisition on the glacier. Geodetic basis information (e.g. geoid parameters) has been collected from Statens Kartverk (national mapping agency).

After the acquisition, the raw data were pre-processed by TopScan $\mathrm{GmbH}$. The pre-processing comprises the determination of the absolute position and orientation of the laser scan system during the flight by analysis of the timesynchronized differential GPS (DGPS) and INS data, calculation of the relative coordinates, system calibration and finally calculation of the coordinates in UTM/WGS84 format. The primary product delivered is UTM coordinates $(x, y, z)$ of single reflections. A detailed overview on the preprocessing steps is given by Wever and Lindenberger (1999). 
The high density of coordinates allows for the generation of high-resolution DEMs. For the data analysis, two raster DEMs (cell size 1 and $5 \mathrm{~m}$ respectively) were interpolated from all data points within each of the datasets using the SCOP++ software and the linear prediction algorithm (Pfeifer and others, 2001). Data gaps at the glacier tongue (see below) were masked using a nearest-neighbour function. Figure 2 shows the level of detail given in the $1 \mathrm{~m}$ DEMs. For the elevation- and volume-change calculations the area of Engabreen $\left(39.6 \mathrm{~km}^{2}\right)$ was clipped out of the DEMs using the 2001 glacier outline provided by the Norwegian Water Resources and Energy Directorate (NVE). The $5 \mathrm{~m}$ DEMs were used, as it turned out that the $1 \mathrm{~m}$ DEMs have no significant information benefit for this purpose.

\section{Glaciological and GPS field data}

As ground truth, surface elevation profiles were measured with DGPS during, or close in time to, the laser scanner data acquisition. To check the horizontal accuracy of the laser DEMs, the outline of the mountain hut Takeheimen and a crevasse were also measured.

Glacier mass balance was determined for winter, summer and the whole glaciological year using the direct glaciological method. Snow-depth soundings performed between 24 and 28 May 2002 at 160 locations along $33 \mathrm{~km}$ of profiles on the glacier plateau revealed $4.0-7.5 \mathrm{~m}$ of snow. Furthermore, emergence/submergence velocity at ten locations was calculated from repeated surveying using DGPS and surface slopes from the DEM from 24 September 2001.

\section{RESULTS}

\section{Data quality}

Kennett and Eiken (1997) stated that the accuracy of surface elevations is affected principally by uncertainties in laser range $(\sim 7 \mathrm{~cm})$ and GPS position $(\sim 10 \mathrm{~cm})$. Other studies show that in flat and snow-covered parts of a glacier, airborne laser altimetry may be able to reach an elevation change accuracy of $<0.1 \mathrm{~m}$, as shown over the Greenland ice sheet (Krabill and others, 2002). At Unteraargletscher, Switzerland, an elevation change accuracy of 0.5-0.7 m was obtained, as the data acquisition rate and the quality of measurements depend on the slope of the surface and are reduced over crevassed areas (Favey and others, 1999).

The following procedures for assessing the quality of the airborne laser scanning DEMs have been applied:

1. Visual checking of data-point density and data-point distribution.

2. Estimating the sensor position accuracy from GPS reference data.

3. Comparing the $z$ values of the airborne laser scanning DEMs with the control area 'Halsa football field' for assessing the vertical accuracy.

4. Comparing the $z$ values of the airborne laser scanning DEMs with GPS measurements on the glacier.

5. Comparing visualized laser scanning DEMs with shapes of clearly defined objects for assessing the horizontal accuracy.

For all three models, visual checks were applied in order to identify gaps or irregularities in point density. They showed

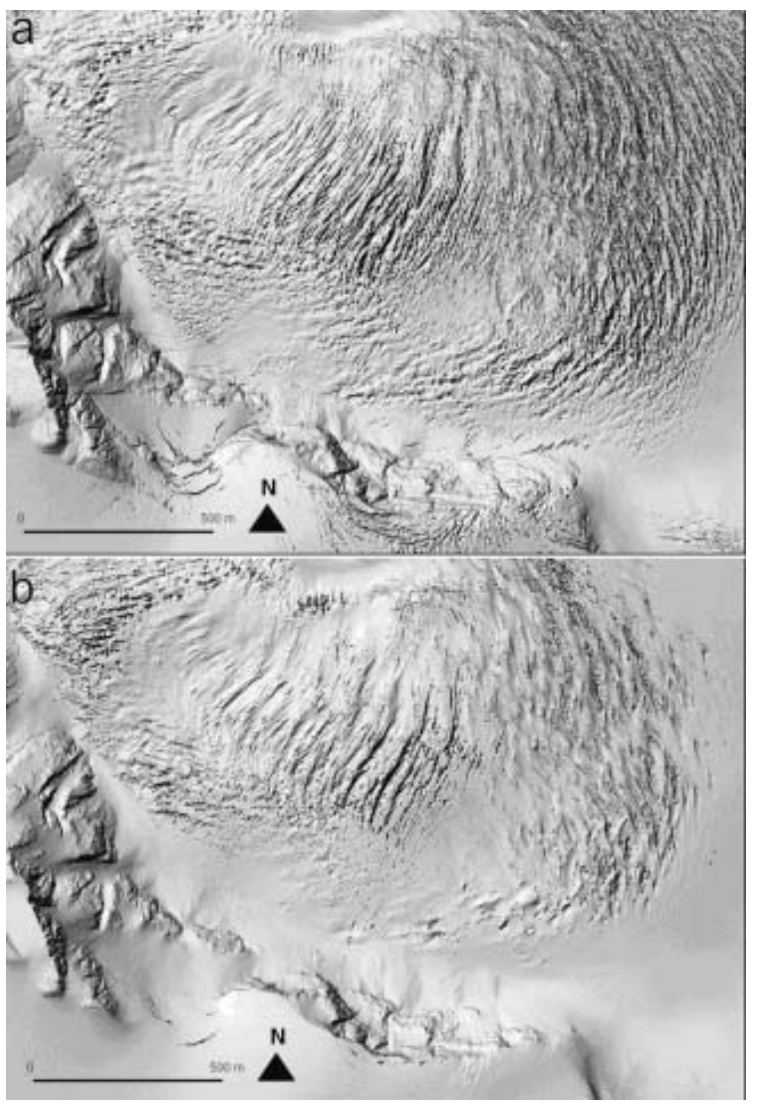

Fig. 2. Visualization of parts of the laser DEMs from September 2001 (a) and May 2002 (b), showing the most crevassed part of Engabreen. The visualization shows the level of detail to be found in the data and the visible difference in surface appearance between the two acquisition dates. It can be deduced that in May snow is covering a substantial part of the crevassed area which was nearly snow-free in September.

an almost equally dense point distribution over most of the scanned areas. No data points, and therefore no coordinates, were collected on water bodies (e.g. Engabrevatnet in front of the Engabreen tongue), as too little of the laser signal is reflected at this type of surface and therefore no measurement is triggered. In all models, gaps on the glacier tongue were identified, probably also due to meltwater or, rather, pure ice causing effects similar to water. In all models, these data gaps comprise $\sim 1 \%$ or less of the whole dataset, and the gaps always lie below $400 \mathrm{~m}$ a.s.l. Although this will not significantly affect the calculation for the whole glacier, we have to keep this in mind when assessing the results on the glacier tongue.

The laser sensor position accuracy during the flight campaign was evaluated in the data pre-processing stage based on the GPS reference data from Bodø, Ørnes and Holandsfjord. The result yields a three-dimensional accuracy of $\sim 0.02 \mathrm{~m}$ (personal communication from TopScan $\mathrm{GmbH}, 2004)$.

The vertical accuracy of the airborne laser scanner DEMs is analyzed using the deviations in $z$ direction from the DEM of the control area in Halsa (Table 2).

The usual method for geo-referencing glaciological in situ data is DGPS measurement, providing a standard to which the position determinations from laser scanner measurements must be compared. During the laser scanner acquisition campaigns on 28 May and 23 August 2002, 
Table 2. Comparison of elevation of laser scanning point data with a reference surface derived from tachymetric data at the control area 'Halsa football field' (laser points - DEM control area)

\begin{tabular}{lccccc}
\hline Date & Laser points on control area & Max. $\Delta Z$ & Min. $\Delta Z$ & Mean $\Delta Z$ & Std dev. $\Delta Z$ \\
& & $\mathrm{~m}$ & $\mathrm{~m}$ & $\mathrm{~m}$ \\
\hline 24 Sept. 2001 & 3231 & 0.30 & -0.31 & 0.00 & 0.09 \\
28 May 2002 & 3361 & 0.35 & -0.25 & 0.00 & 0.08 \\
23 Aug. 2002 & 2765 & 0.44 & -0.28 & 0.01 & 99.97 \\
\hline
\end{tabular}

elevation profiles were measured simultaneously on the glacier surface using an Ashtech Z-Surveyor receiver with the antenna mounted on a tripod on a snow scooter. On 24 September 2001 the positions of nine ablation stakes in the upper part of Engabreen were measured. For differential correction, a second receiver was running at the geodetic control point Holandsfjord. The comparison of the GPS $z$ values with corresponding $z$ values of the laser scanner

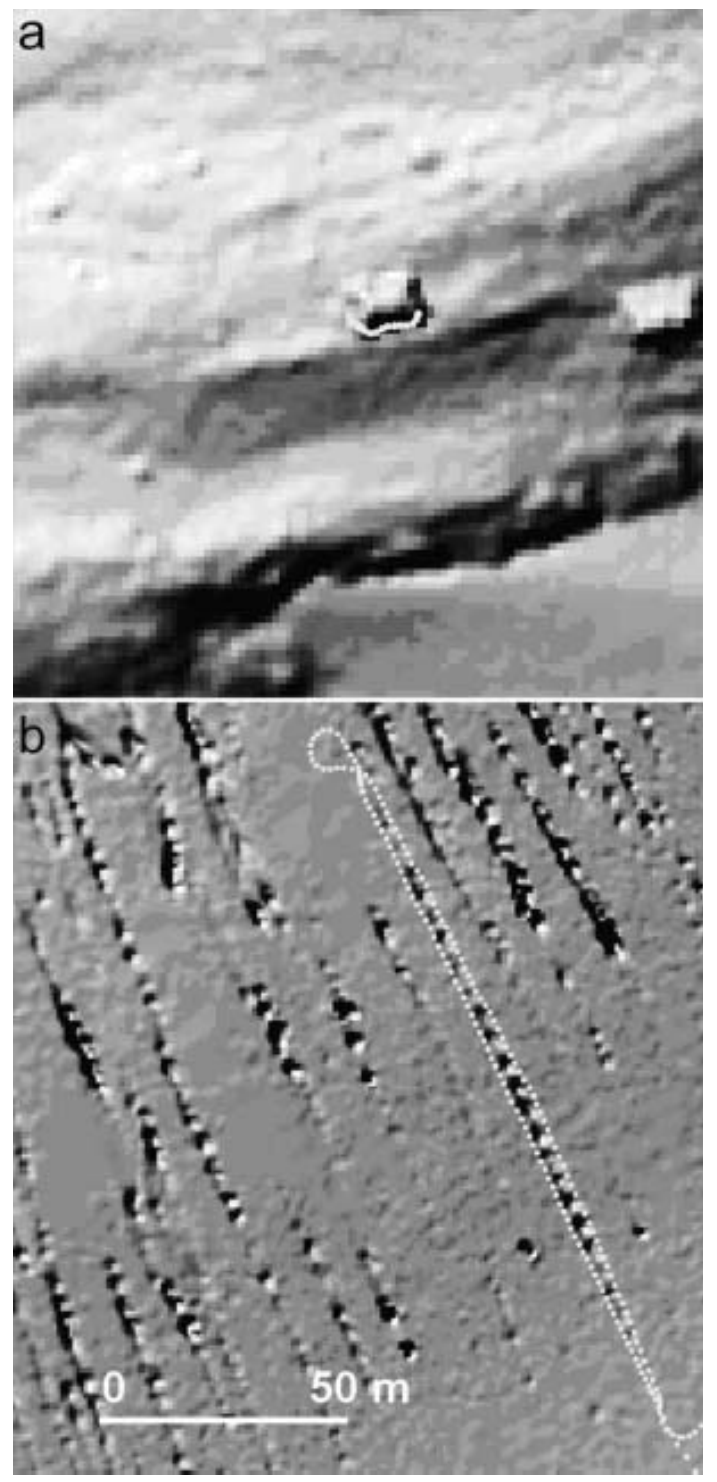

Fig. 3. Hillshade of the $1 \mathrm{~m}$ DEM of 23 August 2002 showing the hut Tåkeheimen (a) and a crevasse in the northern part of Engabreen (b). The dotted line shows GPS positions (southern side of hut and outline of crevasse) from the same day.
DEM (Table 3) shows minimal deviations for the data acquisition campaigns in May and August.

A means for the validation of the horizontal accuracy of the laser DEMs is the comparison with clearly shaped objects in the scan area (Fig. 3). The comparison result is similar for all three models, indicating a high relative accuracy; this is important for the reliability of the multitemporal calculations.

\section{Glacier elevation and volume change}

Average surface elevation change, and subsequently space volume change, was calculated for the winter balance term (flight 24 September 2001-flight 28 May 2002), the summer balance term (flight 28 May 2002-flight 23 August 2002) and the net balance term (flight 24 September 2001-flight 23 August 2002). The results are shown in Figures 4 and 5 (thin lines).

The average elevation change for the winter term is $5.0 \pm 0.2 \mathrm{~m}$, and the winter volume change is $(198 \pm 8) \times 10^{6} \mathrm{~m}^{3}$. The average elevation change for the summer term is $-5.7 \pm 0.2 \mathrm{~m}$, and the summer volume change is $(-224 \pm 8) \times 10^{6} \mathrm{~m}^{3}$. Both curves show anomalous patterns in the elevation bands between 600 and $900 \mathrm{~m}$ a.s.l. (more positive values in winter, more negative values in summer), which corresponds to the highly crevassed transition zone from the plateau to the icefall and tongue of Engabreen. During winter, most crevasses are covered by snow, and elevation is overestimated by comparison with non-crevassed parts of the glacier (Fig. 2). During summer, the effect is the opposite.

The net result gives negative values all over Engabreen, with an average elevation change of $-0.6 \pm 0.2 \mathrm{~m}$ and consequently a volume change of $(-25 \pm 8) \times 10^{6} \mathrm{~m}^{3}$. The results in the lowermost elevation bands must be treated with care due to the changing glacier border and the data gaps in the airborne laser scanner data (see above).

\section{Snow depth, ice melting and glacier volume change}

Traditional mass-balance field measurements have been performed at Engabreen annually since 1970. In 2002, the summer and net balance measurements were carried out on 26 September 2002. For the comparison with the laser scanner acquisition dates, the mass balance has been recalculated for a balance year ending 23 August 2002. Further, for the comparison with the laser scanner data, the mass balance was transformed to thickness changes (snow depth and melting), ignoring changes in density profiles. The results are shown in Figures 4 and 5 (thick lines).

The winter term is negative below $600 \mathrm{~m}$ a.s.l. due to net glacier melting in this area during the winter (mainly in late autumn and spring). The average thickness change from 
Table 3. Comparison of laser scanning DEMs with GPS point measurements on the glacier surface during the flights (DEM laser-GPS measurements)

\begin{tabular}{|c|c|c|c|c|c|c|}
\hline Date & Number of GPS point measurements & $\begin{array}{c}\text { Max. } \Delta Z \\
m\end{array}$ & $\begin{array}{c}\text { Min. } \Delta Z \\
\mathrm{~m}\end{array}$ & $\begin{array}{c}\text { Mean } \Delta Z \\
\mathrm{~m}\end{array}$ & $\begin{array}{c}\text { Std dev. } \Delta Z \\
\mathrm{~m}\end{array}$ & $\begin{array}{c}\text { Points with }|\Delta| \leq 0.3 \mathrm{~m} \\
\%\end{array}$ \\
\hline 24 Sept. 2001 & 9 & 0.09 & -0.28 & -0.14 & 0.14 & 100 \\
\hline 28 May 2002 & 5955 & 0.30 & -0.32 & -0.03 & 0.08 & 99.9 \\
\hline 23 Aug. 2002 & 4761 & 0.30 & -0.51 & -0.05 & 0.08 & 99.5 \\
\hline
\end{tabular}

measured snow depth and ice melting was $5.4 \pm 0.4 \mathrm{~m}$, corresponding to a volume change of $(220 \pm 20) \times 10^{6} \mathrm{~m}^{3}$. The average thickness change from melting of snow, firn and ice for the summer term was $-5.0 \pm 0.6 \mathrm{~m}$, corresponding to a volume change of $(-200 \pm 20) \times 10^{6} \mathrm{~m}^{3}$. The net balance curve shows positive values above $1100 \mathrm{ma.s.l}$. which correspond well to the observed position of the transient snowline on 23 August 2002. The average net thickness change for Engabreen was $0.4 \pm 0.7 \mathrm{~m}$, and consequently the volume change was $20 \pm 30 \times 10^{6} \mathrm{~m}^{3}$.

\section{DISCUSSION}

Airborne laser scanning is probably the first airborne method that is accurate enough for measuring intra-annual changes in elevation with sub-metre accuracy over an entire glacier area. The absolute and relative horizontal and vertical accuracies of the laser DEMs calculated here support this assumption.

Comparison of the net balance curves in Figures 4 and 5 reveals a positive mass balance in the upper parts of Engabreen according to the traditional glacier mass-balance data, but a slight surface lowering according to the laser data. This observation, and the obvious general difference between the elevation change curve derived from laser scanner data and the thickness change curve derived from

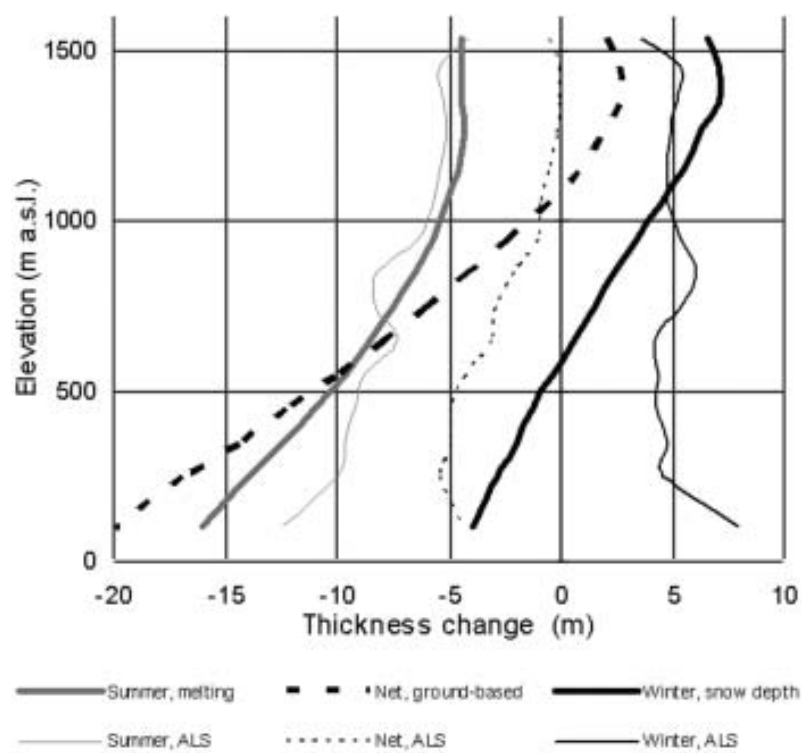

Fig. 4. Average elevation change in altitudinal bands based on airborne laser scanner data (thin lines: ALS) and thickness change based on traditional mass-balance measurements (thick lines) for the summer term, winter term and the adapted balance year. field measurement data, occurs because the elevation change reflects not only the local mass balance, but also a vertical velocity component (Paterson, 1994).

Thus, during winter (September-May) the submergence velocity makes the surface-elevation change less than the winter snow depth in the accumulation area, while in the ablation area the emergence velocity makes the surfaceelevation change greater than the small net ice melting (mainly taking place in autumn and spring).

During summer, the submergence velocity makes the lowering of the surface elevation in the accumulation area larger than the change in snowpack thickness due to melting. In the ablation area, the emergence velocity makes the elevation change less negative than the ice melting. If the glacier were in a steady state, the total volume change during a mass-balance year would equal zero all over the glacier. In fact, a steady-state glacier should have mass surplus at the end of a shorter, adapted mass-balance year since there should be more melting between late August and the end of the regular mass-balance year.

The results imply that the glacier dynamics of Engabreen have not adjusted yet to a recent shift in mass balance. In other words, the glacier is 'too fast'. The mass-balance record shows a large mass surplus between 1988 and 1997 $\left(+1.37 \mathrm{~m}\right.$ w.e. $\mathrm{a}^{-1}$ on average). By contrast, the average net balance between 1998 and 2001 was close to zero.

With this in mind, we now discuss the conditions under which the use of DEMs derived from airborne laser scanning could lead towards a reliable estimation of glacier mass

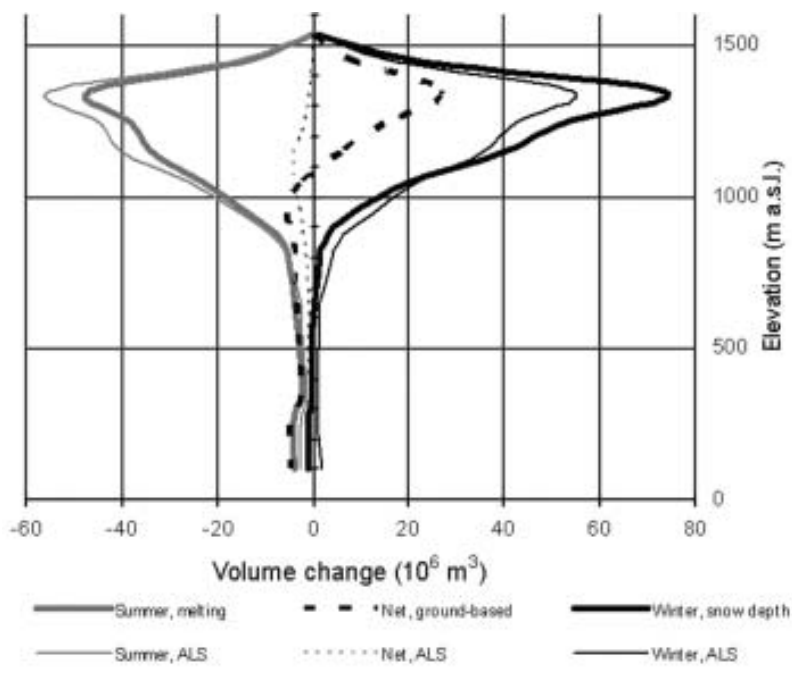

Fig. 5. Volume change based on airborne laser scanner data (thin lines: ALS) and traditional mass-balance measurements (thick lines) for the summer term, winter term and the adapted balance year. 


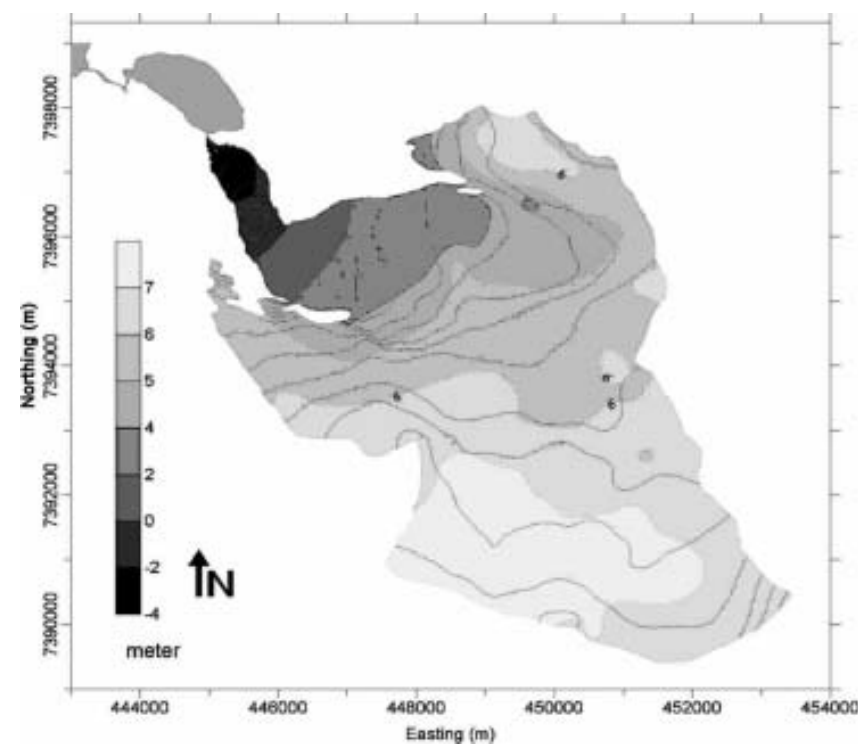

Fig. 6. Distribution of snowpack thickness based on snow-depth soundings in May 2002.

balance. The topics we consider are (1) resolution and accuracy of the method, (2) density issues, and (3) glacier dynamics, especially submergence and emergence velocities.

1. The resolution and accuracy of the method are given with the acquisition parameters used and are verified by the data quality check.

2. On Engabreen, the winter balance water equivalent values were calculated for the entire glacier based on density measurements in two snow pits. It will be worth investigating the spatial and temporal density variations in order to find the correct densities that should be used for transforming volume into mass. This issue will not be discussed further in this paper.

3. As stated above, there are two components influencing the surface elevation of a glacier: one that is controlled by accumulation and ablation and one that is controlled by non-linear dynamic processes. Airborne laser scanning, like other geodetic methods in glaciology, provides little direct information on the underlying explanation for a surface elevation change.

With the datasets available in this study, the submergence and emergence velocities at Engabreen for the winter term of the glaciological year 2001/02 can be estimated as shown in this section. The airborne laser acquisition flight on 24 September 2001 occurred just before the start of the winter accumulation on the glacier. And during the airborne laser acquisition flight on 28 May 2002, traditional winter massbalance measurements were carried out including the estimation of the snowpack thickness based on $\sim 160$ snow-depth measurements in the altitudinal bands above $900 \mathrm{~m}$ (representing $\sim 92 \%$ of the area of Engabreen). Figure 6 shows an interpolated snowpack thickness distribution map based on these data.

Neglecting the effect of glacier dynamics, the snowpack thickness values should correspond approximately to the difference values measured by laser scanning (DEM May$D_{\text {Eep }}$ ). There will be only minor differences (e.g. where the area is crevassed and motion of the crevasses gives a

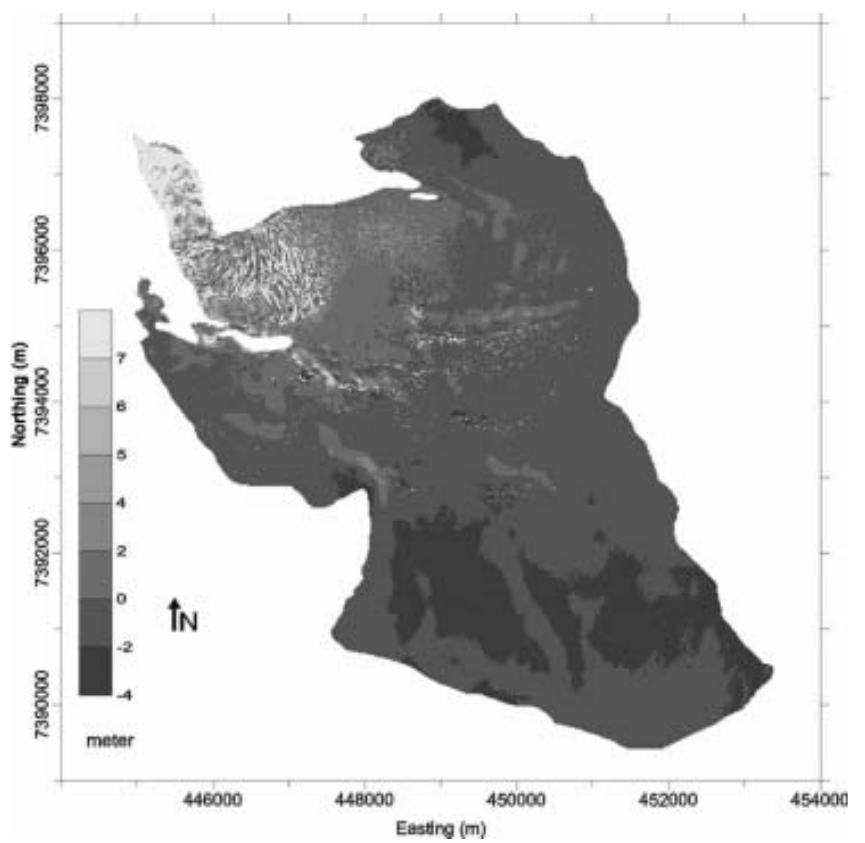

Fig. 7. Distribution of emergence/submergence velocities for the winter term 2001/02 calculated from the elevation difference of the laser DEMs and snowpack thickness derived from snow-depth soundings.

sudden change in surface elevation in the laser scanner difference values). Figure 4, however, shows significant differences between snowpack thickness and successive DEM elevations. The difference must be explained instead, as shown before, with different submergence and emergence velocities, which can be estimated now by subtracting the snowpack thickness from the difference DEM (DEM May DEM $\left.M_{\text {Sep }}\right)$. The interpolated snowpack thickness map was produced from profile lines, which needed to be located in favourable areas for transportation and safety purposes. The crevassed and steep parts of Engabreen are therefore underrepresented and the quantification of the snowpack thickness contains a larger uncertainty there.

Figure 7 shows the result of the calculation: the submergence/emergence velocities on Engabreen for winter $2001 / 02$. As expected, submergence dominates in the area above 1050 ma.s.l., while emergence dominates in the lower parts. Emergence areas above 1050 ma.s.l. may be due to underestimated snow depth (e.g. at steeper leeward slopes) or extraordinarily large elevation change in the difference DEM due to filling or displacement of crevasses.

The emergence/submergence map is now compared to emergence/submergence velocities calculated at 13 locations on the plateau from DGPS positioning in September 2001 and May 2002, and surface slope at the stake locations (see Fig. 1 for stake locations). The difference between the stake values and the DEM values ranges from $0.1 \pm 0.2 \mathrm{~m}$ to $-0.8 \pm 0.2 \mathrm{~m}$ (mean $0.3 \pm 0.2 \mathrm{~m}$ ).

In summary, submergence/emergence velocities can be derived from airborne laser scanning data provided massbalance data are available including reliable snowpack thickness values for the winter period. Conversely, with knowledge of emergence/submergence velocity, reliable estimates of glacier mass balance can be derived. It has further to be investigated how much the vertical velocity component differs from year to year along the longitudinal 
profile of the glacier. Thus, airborne laser scanning is a highly reliable method for determining glacier mass balance.

Forthcoming work on the airborne laser scanner datasets from Engabreen and the other OMEGA datasets from Hintereisferner, Austria, (ten datasets within 1 year) will also contain the reconstruction and analysis of horizontal velocity fields from airborne laser scanner data, which will further improve the applicability of the method as a tool for operational glacier monitoring. An additional advantage of airborne laser scanning for glaciological applications is that the laser signal intensity value, which is recorded for every data point, can be used to classify different surface types (snow, firn, ice), as first investigations show (Lutz and others, 2003).

\section{CONCLUSION}

Airborne laser scanning is not only one more technique for delivering DEMs for glaciological purposes, but is accurate enough for investigating short-term elevation and volume changes. Furthermore, the method allows monitoring over entire glaciers, including snow-covered areas, where lack of texture make photogrammetric methods inaccurate. This is probably the most valuable advantage of airborne laser scanning compared to the traditional photogrammetric approach.

For glaciological applications outside the Greenland ice sheet (where laser altimetry data are abundant) the acquired data within the OMEGA project (four datasets of Engabreen and ten datasets of Hintereisferner) are of worldwide significance, especially for multi-temporal analyses like the calculation of intra-annual changes in glacier extent, volume and mass balance. The resolution of accurate DEMs derived from laser scanning technology is high enough for representing realistic topography (e.g. in crevassed areas). Furthermore visual products like hillshades allow the delineation of the glacier outline due to different surface roughnesses of, for example, ice-free surfaces and glacier ice. Changes in glacier geometry (area, volume) can be accurately calculated from repeated data acquisition. With knowledge of snow and firn density, and assumptions about the glacier dynamics, glacier mass balance can be estimated.

\section{ACKNOWLEDGEMENTS}

The OMEGA project was supported by the Fifth Framework Programme of the European Commission, contract No. EVK2-CT-2000-00069. The authors thank the reviewers for valuable comments and discussion.

\section{REFERENCES}

Abdalati, W. and 9 others. 2002. Airborne laser altimetry mapping of the Greenland ice sheet: application to mass balance assessment. J. Geodyn., 34(3-4), 391-403.

Ackermann, F. 1999. Airborne laser scanning - present status and future expectations. ISPRS J. Photogramm. Rem. Sens, 54, 64-67.
Aðalgeirsdóttir, G., K.A. Echelmeyer and W.D. Harrison. 1998. Elevation and volume changes on the Harding Icefield, Alaska. J. Glaciol., 44(148), 570-582.

Andreassen, L.M., H. Elvehøy and B. Kjøllmoen. 2002. Using aerial photography to study glacier changes in Norway. Ann. Glaciol., 34, 343-348.

Bamber, J.L. and R. Kwok. 2003. Remote sensing techniques. In Bamber, J.L. and A.J. Payne, eds. Mass balance of the cryosphere: observations and modelling of contemporary and future changes. Cambridge, Cambridge University Press, 59-113.

Echelmeyer, K.A. and 8 others. 1996. Airborne surface profiling of glaciers: a case-study in Alaska. J. Glaciol., 42(142), 538-547.

Favey, E., A. Geiger, G.H. Gudmundsson and A. Wehr. 1999. Evaluating the potential of an airborne laser-scanning system for measuring volume changes of glaciers. Geogr. Ann., 81A(4), $555-561$.

Geist, T., E. Lutz and J. Stötter. 2003. Airborne laser scanning technology and its potential for applications in glaciology. In Proceedings of the ISPRS Workshop on 3-D Reconstruction from Airborne Laserscanner and INSAR Data. Dresden, International Society for Photogrammetry and Remote Sensing, 101-106.

Kaser, G., A. Fountain and P. Jansson. 2003. A manual for monitoring the mass balance of mountain glaciers. Paris, UNESCO.

Kennett, M. and T. Eiken. 1997. Airborne measurement of glacier surface elevation by scanning laser altimeter. Ann. Glaciol., 24, 293-296.

Krabill, W., R. Thomas, K. Jezek, K. Kuivinen and S. Manizade. 1995. Greenland ice sheet thickness changes measured by laser altimetry. Geophys. Res. Lett., 22(17), 2341-2344.

Krabill, W.B. and 8 others. 2002. Aircraft laser altimetry measurements of changes of the Greenland ice sheet: technique and accuracy assessment. J. Geodyn., 34(3-4), 357-376.

Kraus, K. 2004. Photogrammetrie Band 1 - Geometrische Informationen aus Photographien und Laserscanneraufnahmen, 7. Berlin, etc., de Gruyter Verlag.

Lutz, E., T. Geist and J. Stötter. 2006. Investigations of airborne laser scanning signal intensity on glacial surfaces - utilizing comprehensive laser geometry modelling and orthophoto surface modelling (a case study: Svartisheibreen, Norway). In Proceedings of the ISPRS Workshop on 3-D Reconstruction from Airborne Laserscanner and INSAR Data. Dresden, International Society for Photogrammetry and Remote Sensing, 143-148.

Paterson, W.S.B. 1994. The physics of glaciers. Third edition. Oxford, etc., Elsevier.

Pellikka, P. and 8 others. 2001. Development of an operational monitoring system for glaciers - synthesis of earth observation data of the past, present and future. In Belward, A., E. Binaghi, P.A. Brivio, G.A. Lanzarone and G. Tosi, eds. Proceedings of International Workshop on Geo-spatial Knowledge Processing for Natural Resource Management. Varese, 283-288.

Pfeifer, N., P. Stadler and C. Briese. 2001. Derivation of digital terrain models in the SCOP++ environment. In OEEPE Workshop on Airborne Laserscanning and Interferometric SAR for Detailed Digital Terrain Models. Stockholm, European Organization for Experimental Photogrammetric Research.

Spikes, V.B., B.M. Csathó and I.M. Whillans. 2003. Laser profiling over Antarctic ice streams: methods and accuracy. J. Glaciol., 49(165), 315-322.

Thomas, R. and 6 others. 2000. Mass balance of the Greenland ice sheet at high elevations. Science, 289(5478), 426-428.

Wever, C. and J. Lindenberger. 1999. Laserscanning - a mapping method gains ground. Photogrammetric Week, 99, 125-132. 